\title{
Hyporesponsiveness to Social and Nonsocial Sensory Stimuli in Children with Autism, Children with Developmental Delays, and Typically Developing Children
}

\author{
Grace T. Baranek ${ }^{1}$, Linda R. Watson ${ }^{1}$, Brian A. Boyd ${ }^{1}$, Michele D. Poe ${ }^{1}$, Fabian J. David ${ }^{1,2}$, \\ and Lorin McGuire ${ }^{1,3}$ \\ ${ }^{1}$ At the time of this study all authors were at the University of North Carolina at Chapel Hill - \\ Chapel Hill, North Carolina. \\ ${ }^{2}$ Currently at the University of Illinois at Chicago - Chicago, Illinois. \\ ${ }^{3}$ Currently at the Autism Consulting \& Educational Services - Dallas, Texas
}

\section{INTRODUCTION}

\begin{abstract}
There is a paucity of developmental research on the nature of unusual responses to sensory stimuli in children with autism despite numerous phenomenological reports that these problems exist from an early age (Grandin, 1996; Hart, 1991; Jones, Quigney, \& Huws, 2003). Prevalence rates of unusual sensory responses are noted in $69 \%$ to $90 \%$ of preschoolers with autism (Baranek, David, Poe, Stone, \& Watson, 2006; Ben-Sasson et al., 2009; Leekam, Nieto, Libby, Wing, \& Gould, 2007). Researchers have characterized some of these unusual sensory features into two behavioral response patterns --

hyperresponsiveness and hyporesponsiveness (Baranek et al., 2006; Ben-Sasson et al., 2009; Hirstein, Iversen, \& Ramachandran, 2001; Miller, Anzalone, Lane, Cermak, \& Olsten, 2007; O'Neill \& Jones, 1997; Schneider et al., 2008). Hyperresponsiveness is an exaggerated behavioral response to sensory stimuli (e.g., aversion to lights, covering ears to sounds, avoidance of touch). Hyporesponsiveness refers to lack of a behavioral response, or insufficient intensity of response to sensory stimuli (e.g., lack of orienting to novel sounds; diminished response to pain). Psychophysiological studies in autism and related populations have validated these two behavioral constructs (Hirstein et al., 2001; Miller, Reisman, McIntosh, \& Simon, 2001).
\end{abstract}

These two sensory response patterns - hyper- and hyporesponsiveness - are reported to coexist in children with autism (Baranek et al., 2006; Greenspan \& Wieder, 1997; Hirstein et al., 2001; Miller et al., 2007); however, hyporesponsiveness appears more prevalent and specific to autism during early childhood (Baranek et al., 2006; Ben-Sasson et al., 2009; Rogers \& Ozonoff, 2005). Some studies have matched autism samples to typically developing controls, but few included developmentally delayed (DD) comparison groups to determine the uniqueness of these features. One study utilizing a parent-report questionnaire demonstrated that a pattern of sensory hyporesponsiveness significantly distinguished

Copyright () 2012 by Cambridge University Press. All rights reserved.

Address all correspondence to: Grace T. Baranek, Ph.D. - Professor, Division of Occupational Science (CB \#7122) University of North Carolina at Chapel Hill - Chapel Hill, NC 27599-7122 Phone: 919.843.4467 Fax: 919.966.9007 gbaranek@ med.unc.edu.

Publisher's Disclaimer: Manuscript has been accepted for publication and will appear in a revised form, subsequent to editorial input by Cambridge University Press, in Development \& Psychopathology published by Cambridge University Press. 
children with autism from controls, both typically developing and DD, with comparable mental ages (Baranek et al., 2006).

The developmental nature of sensory hyporesponsiveness in children with autism has not been fully explicated and its association with broader developmental outcomes is unclear. Results from cross-sectional studies utilizing parent report formats have been mixed, with some researchers reporting sensory features increasing (e.g., Talay-Ongan \& Wood, 2000) and others reporting the same features decreasing (e.g., Baranek et al., 2006; Leekam et al., 2007) with age. Discrepancies across studies may be attributable to methodological differences in matching procedures (e.g., nature of comparison groups), sampling procedures (e.g., broad or narrow age range), analytic procedures (e.g., treating age as a categorical versus continuous variable), as well as outcome variables (e.g., format and sensitivity of measures).

Two studies (Lane, Young, Baker, \& Angley, 2010; Liss, Saulnier, Fein, \& Kinsbourne, 2006) suggest that there may be an association between parent reported levels of sensory hyporesponsiveness and standardized measures of adaptive behavior in a subgroup of children with autism. Additionally, Liss et al. (2006) found poorer communication and social performance was related to high levels of hyporesponsiveness in a subgroup of school-aged children with autism. Uncovering developmental differences in hyporesponsive sensory patterns across various stimuli and contexts with more rigorous methodologies, and in comparison to children with other developmental delays as well as typically developing children, may elucidate the pathogenesis of these features in autism.

Given the core deficits that define autism spectrum disorders, researchers have debated whether hyporesponsiveness to sensory stimuli is a generalized phenomenon, or whether hyporesponsiveness is limited to social contexts in this population (Baranek et al., 2006; Dawson, Meltzoff, Osterling, Rinaldi, \& Brown, 1998; Dawson et al., 2004; Mundy \& Newell, 2007; Swettenham et al., 1998). The answer to this question also has implications for understanding causal mechanisms underlying the development of autistic features. Theoretically, a young child who does not overtly respond to novel sensory stimuli in the natural environment may miss numerous learning opportunities as well as sociallycontingent responses that are foundational to social-communication and subsequent adaptive development. Lack of response to social stimuli may be particularly detrimental to a child's learning potential, because a substantial amount of knowledge early in development, and throughout the lifespan, is acquired through interactions with others. However, nonsocial sensory stimuli naturally occurring in the child's environment also present rich opportunities for sharing attention, communicating, and making meaning of those sensory experiences.

Behavioral orienting is one measure of a child's responsiveness to novel sensory events, and the development of sensory orienting often has been investigated in typically-developing infants using gaze shifting paradigms in several prospective studies (Farroni et al., 1999; Hunnius \& Geuze, 2004; Johnson, 1990; Rothbart, Posner, \& Rosicky, 1994). Newborn infants have intact orienting responses to a variety of social (e.g., faces, voices) and nonsocial sensory (e.g., lights flashing; geometric patterns) stimuli, and latency of response decreases with maturation across the first year of life. By 4-5 months of age, typicallydeveloping infants are able to disengage easily from a competing stimulus in a central field to overtly shift their visual attention to a novel stimulus in their periphery. These inhibitory responses of visual disengagement and gaze shift are thus integral to orienting to novel sensory stimuli in the presence of distracters, and appear mediated by subcortical mechanisms (e.g., superior colliculus) connecting with parietal and frontal structures that mature over time. 
Some neuropsychological theories have focused primarily on orienting deficits in the context of social stimuli to account for core symptoms in autism (Dawson et al., 1998; Dawson et al., 2004; Swettenham et al., 1998), while others have implicated more generalized deficits in orienting and/or attention disengagement mechanisms that could explain hyporesponsiveness to sensory stimuli across both social and nonsocial contexts, as well as downstream consequences on social-communication (Harris, Courchesne, Townsend, Carper, \& Lord, 1999; Townsend et al., 1999; Zwaigenbaum et al., 2005).

Orienting responses to naturally-occurring social and nonsocial sensory stimuli have been studied as a predictor of autism diagnostic status. Failure to attend appropriately to stimuli in a social context (e.g., lack of response to a person calling the child's name) was frequently identified to be one of the earliest and specific clinical manifestations of autism (Dawson et al., 1998; Nadig et al. 2007; Landa, Holman, \& Garrett-Mayer, 2007; Wetherby, Watt, Morgan, \& Shumway, 2007; Zwaigenbaum et al., 2005), and furthermore, was considered an important developmental precursor of joint attention (Dawson et al., 2004). Some studies have demonstrated that social orienting was correlated specifically with joint attention and/ or language in young children with autism (Dawson et al., 2004; Leekam \& Ramsden, 2006). Non-social orienting to sensory stimuli has been less investigated. Dawson and colleagues (1998) reported no statistically significant correlation between non-social orienting and joint attention in children with autism at an average chronological age of 5 years. However, another noteworthy finding was that nonsocial orienting significantly discriminated between children with autism from those with DD as well as typicallydeveloping children (Dawson et al., 1998; Dawson et al., 2004), suggesting the possibility of a more generalized deficit in orienting to sensory stimuli.

Some researchers suggest that development of joint attention relies upon two interacting attention-regulating systems, the earlier-developing posterior (parietal) and the laterdeveloping anterior (frontal) neural networks (Posner \& Rothbart, 2007). The integration of these two generalized attention networks is hypothesized to be deficient in autism, potentially resulting in impaired joint attention abilities (Mundy \& Newell, 2007; Mundy \& Jarrold, 2010). Prospective studies have also demonstrated that joint attention, especially response to bids from others, is predictive of rate of language growth into the school years for children with autism (Siller \& Sigman, 2008). Thus, deficits in early-developing attentional systems, which may be measured in part by general impairments in orienting to social as well as nonsocial sensory stimuli, theoretically may have cascading developmental consequences on later-developing social-communicative functions including joint attention and language development, and profound effects on the long-term prognosis of a child with autism (Dawson et al., 2004; Mundy \& Neal, 2001; Mundy \& Jarrold, 2010).

In summary, the existing literature suggests that young children with autism have high levels of sensory features, particularly hyporesponsiveness, or lack of orienting, to sensory stimuli. Although orienting to social stimuli has been shown to be deficient in autism, the results for nonsocial sensory stimuli have been mixed. Moreover, several neuropsychological theories purport a specific role for social orienting deficits as a developmental precursor for core social-communicative impairments (e.g., joint attention and language) in autism; however, orienting to nonsocial sensory stimuli has not been sufficiently investigated. Thus, questions still exist regarding whether or not children with autism show a generalized pattern of sensory hyporesponsiveness, and to what degree hyporesponsiveness is affected by various contextual factors (social vs. nonsocial stimuli), stimulus modalities (tactile vs. auditory vs. visual), and/or maturational changes (mental age or chronological age). Likewise, more research is needed to understand associations between generalized sensory hyporesponsiveness and broader developmental outcomes. 
The purpose of this study was to describe sensory hyporesponsiveness to social and nonsocial stimuli as a function of developmentally-related maturation in a large crosssectional sample, to determine the degree to which hyporesponsiveness is generalized across contexts in young children with autism relative to controls, and the extent to which it is associated with broader social-communication outcomes. The specific research questions were:

1. To what extent do scores on an observed measure of sensory hyporesponsiveness in a laboratory task converge with a parent-report measure of sensory features?

2. To what extent do maturational variables (chronological and mental age) affect children's levels of hyporesponsiveness to sensory stimuli across groups?

3. Do children with autism, children with DD, and typically developing children differ in their levels of hyporesponsiveness to sensory stimuli?

4. Does context (social versus nonsocial) affect level of hyporesponsiveness to sensory stimuli across sensory modalities, and if so, does it have differential effects across groups?

5. Is sensory hyporesponsiveness to either social or non-social stimuli associated with behavioral indices of joint attention and receptive and expressive language?

We hypothesized that (a) a behavioral measure of hyporesponsiveness would be significantly correlated with parental reports of hyporesponsiveness in both social and nonsocial contexts, (b) children with autism would show a generalized pattern of hyporesponsiveness across sensory stimuli in both social and nonsocial contexts, (c) this pattern would significantly differentiate the autism group from both comparison groups, , and (d) hyporesponsiveness to sensory stimuli in both social and nonsocial contexts would be negatively correlated with joint attention skills and language abilities.

\section{METHOD}

\section{Participants}

Three groups of children $(\mathrm{N}=178)$ ranging in age from 5 to 105 months were included in this study: Children with autism ( $\mathrm{N}=63$, ages 20-83 months), children with developmental delays (DD) ( $\mathrm{N}=47$, ages 11-105 months), and typically developing children (TD) ( $\mathrm{N}=68$, ages 5-79 months). Tables 1 and 2 provide sample characteristics. Families received monetary incentives (\$25-75) dependent upon their participation in a larger study, which typically included several hours of developmental testing, diagnostic confirmation, and various sensory assessments processing assessments. The children received a small toy or book for their participation. Using convenience sampling, participants were recruited through diagnostic evaluation clinics, early intervention/day care programs, mental health centers, local agencies, parent support groups, and public schools in the state of North Carolina. In addition, the University of North Carolina Subject Registry was used to directly recruit families of children with autism.

Children in the autism group were diagnosed with Autistic Disorder by a licensed psychologist or physician, confirmed by the Autism Diagnostic Interview-Revised (ADI-R; Lord, Rutter, \& Le Couteur, 1994), and the Autism Diagnostic Observation Schedules (ADOS; Lord, Rutter, DiLavore, \& Risi, 1999) or the Childhood Autism Rating Scale (CARS; Schopler, Reichler, \& Renner 1986).

The DD group comprised children with (a) known developmental disabilities and genetic syndromes associated with intellectual disability (i.e., Down, Williams, Prader-Willi, Patau syndromes) $(\mathrm{N}=20)$ and (b) nonspecific idiopathic developmental delay (i.e., IQ > 2 
standard deviations below the mean, or delays $>1.5$ standard deviations below the mean in at least two developmental domains including expressive language, receptive language, cognitive/visual reception, fine or gross motor, and/or adaptive behavior) $(\mathrm{N}=30)$. We excluded children from the DD group if they had a clinical diagnosis of an autism spectrum disorder (ASD) and/or met criteria for "Autism" on the ADOS (new scoring algorithm by Gotham, Risi, Pickles, \& Lord, 2007). There were two cases where children in the DD group with low mental ages (11 and 13 months) met ADOS cut-offs for "ASD", but these findings were discrepant from other autism assessments, and the overall clinical impressions were consistent with their existing diagnoses of DD (not ASD).

The TD group had neither significant developmental problems nor received any special education/therapy services. They all scored within the normal range on developmental assessments. Exclusionary criteria for all groups included the following: co-morbid conditions of autism (e.g., fragile X), mental age (MA) < 6 months, severe physical impairment (e.g., cerebral palsy), uncorrected visual or hearing impairment, and/or currently taking psychoactive medications (including stimulants), as reported by parents or medical records.

\section{Instruments}

Sensory Processing Assessment-The Sensory Processing Assessment (SPA; Baranek, 1999b) is a 20-minute play-based behavioral observation tool administered in a semi-structured format. It is designed to assess sensory response patterns (hyper- and hyporesponsiveness) in young children with autism and related DD from approximately 6 months through 6 years of age. The SPA enables naturalistic observation of a child's behavioral responses to tactile, auditory, and visual sensory modalities in social and nonsocial contexts through playful interaction with novel sensory experiences. There are several sections to the SPA: approach/avoidance to novel toys, orienting to unexpected sensory stimuli, habituation to a repeated stimulus, and presence/absence of unusual sensory seeking behaviors. The orienting subscale was used as the primary outcome measure of hyporesponsiveness in this study; procedures are described in detail below. Test-retest reliability between two raters $(n=64)$ was calculated using Intra-Class Correlations (ICCs) and yielded high reliability (ICC $=.920$ for all 6 orienting items; .917 for the three social items; .867 for the three nonsocial items.)

Sensory Experiences Questionnaire-(SEQ Version 2.0; Baranek, 1999a; Baranek et al., 2006). This brief questionnaire asks parents to respond, on a 5 point Likert scale, to 30 questions about the frequency of their child's responses to sensory stimuli in the context of daily activities and routines. The SEQ has been validated for children with autism, DD, and typically developing children ages 6 months through 6 years, with a demonstrated ability to discriminate sensory features among known diagnostic groups (Baranek et al., 2006). Little et al., (2011) have reported high levels of internal consistency $(\alpha=.80)$, and test-retest reliability $(\mathrm{ICC}=.92)$. Summary scores may be derived for hyper- and hyporesponsiveness to both social and nonsocial stimuli.

Mullen Scales of Early Learning (MSEL; Mullen, 1995)—Four directly administered scales evaluate visual reception, fine motor, receptive language and expressive language abilities in children birth to 68 months of age. The MSEL yields standardized T scores as well as age equivalents for the four scales. The test was standardized on a sample representative of the U.S. population and has acceptable levels of validity and reliability.

Preschool Language Scale-4-(PLS-4; Zimmerman, Steiner, \& Pond, 2002). Parent report, responses to directly administered items, and observation of incidental 
communication throughout the assessment are used to assess language understanding (PLSAC) and expression (PLS-EC) of children from birth to 6 years 11 months. The PLS-4 is standardized on a large sample representative of the 2000 U.S. census data, and has acceptable levels of validity and reliability.

Joint Attention Assessment-The Joint Attention Assessment was developed from tasks used by other investigators (Brady, Steeples, \& Fleming, 2005; Leekam, Hunnisett, \& Moore, 1998; Mundy et al., 2003; Stone, Ousley, Yoder, Hogan, \& Hepburn, 1997), with four goals: (a) a specific focus on measuring response to, and initiation of joint attention; (b) reliable and efficient scoring during administration rather than requiring later video coding; (c) interaction contexts that would appeal to children across a range of ages and functioning levels; and (d) measurement of variability in performance within and between groups of children. No single previous measure of joint attention would allow us to meet all of these goals. This measure included eight trials to assess response to joint attention (RJA), interspersed with eight trials to provide contexts for initiation of joint attention (IJA). Interrater reliability $(\mathrm{n}=53)$ between two raters was substantial (Total JA Score: $87.9 \%$ exact agreement \& kappa=.749; RJA: $91.3 \%$ exact agreement \& kappa=.831; IJA: 82.8\%.exact agreement \& kappa=.666). In addition, Hurwitz (2010) examined convergent validity between RJA scores on the Joint Attention Assessment (potential range of 0 to 8 ) and scores on the response to joint attention item of the ADOS (potential range of 0 to 3 ), using data from a sample of 32 children with autism. A strong significant correlation was found between the scores $(r=.85, p<.001)$.

Procedure

Project staff contacted interested families via telephone, screened participants for eligibility, and scheduled the onsite assessments to confirm diagnostic groupings. Assessments took place at the project laboratory in a community-based location with a child-friendly space. Two half days were typically sufficient to complete all assessments but this varied depending upon the child's age and developmental level.

Parent-completed assessments included a demographic form, a background information questionnaire, and the Vineland Adaptive Behavior Scales (VABS; Sparrow, Balla, \& Cicchetti, 1984). The ADI-R was administered only to parents of children with autism for diagnostic confirmation. Children in all three groups received a vision and hearing screening to confirm normal or corrected normal vision and hearing, and the CARS. Following the screening, children received a standardized cognitive assessment appropriate to their age and developmental level - either the Mullen Scales of Early Learning (Mullen, 1995), Leiter International Performance Scale - Revised (Roid \& Miller, 1997), and/or Bayley II- Mental Developmental Index (Bayley, 1993). Nonverbal mental age (MA) was used as a measure of intellectual functioning in this study to maintain independence from the primary outcomes measures that involved language functions. Thus, on the MSEL, the Visual Reception scale was used to estimate nonverbal MA, whereas the Receptive and Expressive Language scales were used as measures of language age. Participants also completed the PLS-4 (Zimmerman et al., 2002) and the Joint Attention measure. In addition, the autism and DD groups received the ADOS (Lord et al., 1999).

The SPA was administered in a small room with child-sized furniture, a short bookcase that held opaque boxes for supplies, and a few pieces of child art displayed on the walls. If necessary, a parent/familiar adult was present for the assessment to minimize the child's anxiety. The adult was allowed to sit with the child, but was not allowed to comment on the sensory stimuli or interact with items, so that all children had similar instructions and 
procedures. Some parents opted to view the assessments from an adjoining observation room.

The SPA was administered to the child by a trained research assistant (RA) and videotaped for reliability scoring. The SPA orienting subscale consisted of six items, counterbalanced for three modalities (tactile, auditory, visual) and two contexts (social, nonsocial). The six stimuli were administered unexpectedly in the periphery during a competing condition (attention disengagement condition) while the child was engaged visually with a toy at midline while seated on the floor. The presence or absence of orienting responses and latency to orient, as measured by the number of trials to demonstrate an orienting response, were scored. Each stimulus was unimodal - two were auditory (sound stick, name call), two were visual (penlight, hand wave), and two were tactile (air puff, shoulder tap). Three of these stimuli were social in context - intended to obtain the child's response to stimuli with an apparent social purpose (name call, shoulder tap, hand wave). The other three stimuli were nonsocial in context - intended to have no apparent social purpose (sound stick, air puff, penlight). Attempts were made to match the social and nonsocial stimuli in terms of duration/frequency, distance, and intensity (i.e., tactile $=2$ puffs/taps per second presented behind the child; auditory = similar decibel levels of voice/sound stick activated 3-5 feet away from child; visual = 2 flashes/waves administered per second; 18-24 inches away from child), however, some variation across coders and contexts occurred given the nature of testing young children in semi-structured play situations. Previous studies have used similar quasi-experimental procedures that were judged to be ecologically valid (Dawson et al., 1998; Dawson et al., 2004). Each target stimulus was presented to the child as s/he was engaged with a distracter (quiet toy held at midline). Stimuli were interspersed among the toys in the SPA to maximize novelty and minimize habituation, and right/left presentations of stimuli were counterbalanced across subjects. Orienting was measured behaviorally by the child's eyes and/or head visibly disengaging from the central stimulus and turning in the direction of the unexpected, novel stimulus. All competing environmental distractions were minimized. Each stimulus was repeated until a clear behavioral orienting response was observed, to a maximum of three trials. Thus, possible orienting scores for each item were: 1, 2, 3 (corresponding to the trial during which the child responded), and 4 (no response). A cut off of three trials was established because very few children during pilot testing responded after the third trial.

Sum scores were calculated to achieve an overall orienting mean (average of all six items), social mean (3 items), non-social mean (3 items), auditory mean ( 2 items), visual mean (2 items), and tactile mean ( 2 items). Higher mean scores indicate less responsiveness to sensory stimuli. Cronbach's alpha was computed on a subsample of 64 cases used in the reliability analyses. Internal consistency of the scales was computed, with the caveat that only 3 items comprised each subscale ( 3 social items alpha $=.561 ; 3$ nonsocial items alpha $=.556 ; 6$ items total alpha $=.649)$. All items contributed relatively equally to the total scale alpha.

Three research assistants (RAs) were trained by the first author to administer and score the SPA to criterion ( $\geq 90 \%$ agreement by section). On completion of the preliminary training protocol, the first author viewed videotapes of all training administrations to ensure procedural fidelity. The RAs then independently administered and scored the SPA. No rater was aware of any specific research aims. All assessments were videotaped and archived. Periodic reliability checks were completed to confirm procedural fidelity and inter-rater reliability. Due to transitions in personnel over the course of a multi-year project, one new coder independently scored all SPA videos that had been previously coded by one of three original coders for added consistency. Consensus scores were determined for any items with 
disagreements between the new coder and previous coders, and these consensus scores were used in the statistical analyses.

The Joint Attention Assessment followed the SPA administration and was conducted in the same room. The child was seated at a child-sized table directly across from the examiner. Pictures were placed on the walls 90 degrees to the child's right and left side, four pictures per side. Four of the RJA trials directed the child's attention to the left, and four to the right; a graduated sequence of cues was used, from head turn alone to head turn with a point, to head turn with a point and verbal directive "Look," to head turn with point and verbal labeling of the target. Turning the head at least 45 degrees in the indicated direction following the cue was scored as a correct response. For the interspersed IJA trials, materials were presented on the table; activities included pulling toys from an opaque bag, looking at a book that included three defaced pages, and providing a bin of dress-up clothes, among others. The child was credited with a correct response if at any time during each trial s/he initiated alternating gaze between an object and the examiner, used a gesture such as pointing or showing accompanied by eye contact and/or a vocalization, or verbally commented on the activity accompanied by eye contact and/or a gesture directed at the examiner. RAs were trained to administer the items consistent with guidelines in an assessment manual, with observation and feedback provided by the second author. In addition, the RAs were required to achieve at least $80 \%$ reliability in scoring both the RJA and IJA portions for three consecutively scored videotaped assessments as part of the training process. Periodic reliability checks were completed to confirm procedural fidelity and inter-rater reliability at greater $\geq 80 \%$ for the RJA and IJA scoring. Scoring was derived by crediting one point for each trial on which the child exhibited RJA or IJA skills, respectively. To allow for the inclusion of JA scores in cases when not all trials were administered or a trial was later invalidated due to procedural errors, we took the total number of points awarded for RJA or IJA trials and then divided by the number of valid trials administered; thus, the JA scores included in our analyses ranged from 0 to 1 . Higher scores indicate better joint attention skills.

Due to the large number of children with autism or DD who scored at the floor of the standardized scores on the MSEL Receptive and Expressive Language scales and PLS-4, we computed a ratio score of the age equivalent score/chronological age for each child on each language measure. This eliminated floor effects in the language measures for children in all groups. A mean of the two ratio scores was used to represent composite scores for receptive and expressive language, respectively.

\section{Analyses}

To answer our first question, we used Pearson correlations to examine the convergent validity between our laboratory measure of sensory hyporesponsiveness (i.e., SPA orienting subscale) with a parent-report measure (i.e., SEQ). For the remaining questions, inferential analyses were performed by fitting a series of censored regression models. All analyses controlled for mother's education and child's gender because there were significant group differences for these variables. A review of the descriptive data revealed that a number of the subjects scored at the minimum and maximum scores resulting in truncated normal distributions. For this reason, repeated-measures Tobit censored regression models (Stata Press, 2007) were fit. These models allow us to simultaneously account for the floor and ceiling effects in the sensory measure as well as repeated measures within subjects. They also allowed us to directly test whether there were significant differences between the contexts (social versus non-social) in sensory responsiveness. The first set of analyses examined the association between CA, MA and hyporesponsiveness score, as well as group differences and context interactions. Then the association between hyporesponsiveness and joint attention or language was examined by adding these variables to the previously 
described censored regression models. This involved fitting 4 separate models, which included either language (receptive and expressive) or joint attention (RJA and IJA) as a predictor along with group, context, MA, gender, and mother's education as covariates.

\section{RESULTS}

The first analysis determined that total scores on the laboratory measure of hyporesponsiveness (i.e., SPA orienting subscale) were significantly positively correlated with total scores on the parent-report measure (i.e., SEQ), $\mathrm{r}=.39, p<.001$. Examining stimulus contexts separately, the SPA was correlated positively with the SEQ for both social $(\mathrm{r}=.34, p<.001)$ and nonsocial sensory items $(\mathrm{r}=.25, p=.005)$.

Descriptive statistics in Table 3 show the frequencies of children in each group that responded across individual trials for each of the sensory stimuli on the SPA. Figure 1 graphically depicts the percent of children who oriented to any of the three trials across the six sensory stimuli, and denotes a trend for greater orienting for the typical group and lesser orienting for the autism group across stimuli in different modalities. Mean scores for hyporesponsiveness in social or nonsocial contexts, as measured by the first trial to which a child oriented, are summarized in Table 4.

To answer the question of whether maturational variables accounted for degree of hyporesponsiveness across groups, the regression analyses demonstrated that hyporesponsiveness decreased in all groups as a function of $\mathrm{CA}(\beta=-.020, p<.001)$ or MA $(\beta=-.023, p<.001)$. We found that MA (controlling for CA) accounted for a significant amount of the variance in hyporesponsiveness across the groups $(\beta=-.020, p=.005)$, and used this developmental variable as the basis for the remaining analyses.

To answer the next two questions: (a) to what degree the groups differ in level of hyporesponsiveness, and (b) to what degree context (social versus nonsocial) affected the level of hyporesponsiveness across the groups, the regression analysis was examined and indicated that group differences were present but depended upon the 2-way interactions with MA and context. However, the 3-way Group X MA X Context was not significant $\left(\chi^{2}=\right.$ $1.11 ; \mathrm{p}=.57)$ and was dropped from the model. Specifically, when looking at MA (controlling for $\mathrm{CA}$ ) we found an overall significant difference between the groups in developmentally-related change ( $\left.\chi^{2}=7.76, p=.021\right)$ across the social and nonsocial contexts combined. At 6 months mental age, the autism group showed significantly higher scores (i.e., more hyporesponsiveness) than the DD and TD groups. (Table 5 shows model group differences.) By 60 months mental age there were no significant differences among groups. (See Figures 2 and 3.) The difference in the size of the group effect varied significantly between social versus non-social contexts $\left(\chi^{2}=13.83, p=.001\right)$, with a larger effect size for the social context. (See Tables 5 and 6 .) There were no statistically significant differences between the DD and TD groups (all $\mathrm{p}>.10$ ).

Our last question inquired as to whether sensory hyporesponsiveness was associated with behavioral indices of joint attention and language across the three groups. We found that RJA showed a significant negative correlation with hyporesponsiveness $(\beta=-.83, \mathrm{SE}=.37$, $p=.025$ ) and did not vary significantly by group or context (social or nonsocial). However, there was a significant interaction with MA $(\beta=.047, \mathrm{SE}=.02, p=.026)$ resulting in a significant correlation at younger MA (e.g., at 6 months: $\beta=-1.71, \mathrm{SE}=.46, p<.001$ ) but not at older MA (e.g., at 60 months: $\beta=.80, \mathrm{SE}=.90, p=.38$ ). The results for IJA were similar with a significant negative correlation between hyporesponsiveness and IJA ( $\beta=$ $-1.63, \mathrm{SE}=.59, p=.006$ ) that did not vary significantly by group or context (social or 
nonsocial). The IJA X MA interaction showed a non-significant trend ( $p=.063)$ in the same direction as the findings for RJA.

The autism group also showed a significant negative correlation between sensory hyporesponsiveness and language such that children with more problems responding to sensory stimuli had lower language ratio scores (LA/CA). This was true for both receptive $(\beta=-2.0, \mathrm{SE}=.68, p=.004)$, and expressive language ratio scores $(\beta=-2.1, \mathrm{SE}=.73, p=$. 005 ), and did not vary as a function of social versus nonsocial context (all $p>.10$ ). The language ratio X MA interactions were statistically non-significant (both receptive and expressive, $p>$.10). The correlations between hyporesponsiveness and language scores in the TD and DD group did not reach statistical significance (all $p>.05$ ).

\section{DISCUSSION}

This study sought to better understand developmentally-related changes in hyporesponsiveness to sensory stimuli in both social and nonsocial contexts in young children with autism, and the potential associations between hyporesponsiveness and broader developmental outcomes. We also aimed to distinguish hyporesponsive sensory patterns in autism from both typical development and delayed development to provide a better understanding for potential neurodevelopmental mechanisms that underlie these intriguing features and their clinical implications.

\section{Convergence of Observed and Parent-report Measures of Sensory Hyporesponsiveness}

The SPA and SEQ had significant positive correlations, indicating convergent validity and supporting the assumption that the results from our observational measure have some generalizability to the child's sensory features as perceived by their parents in everyday life. However, the magnitude of the overall correlation was moderate, indicating that these two measures are also tapping somewhat different aspects of sensory hyporesponsiveness (e.g., broad versus specific), and/or reflect differences related to format (e.g., observed versus parent-report) or context (e.g., familiar versus unfamiliar environments) of the measures. Statistical models utilizing multi-modal measures of sensory features, controlling for measurement format, may be more reliable and provide a more comprehensive understanding of the constructs of interest and their relationship to various developmental outcomes in future research (Boyd et al., 2010).

\section{Developmentally-Related Changes in Sensory Hyporesponsiveness}

The results confirmed that hyporesponsiveness, as measured by a sensory orienting task in the laboratory, was affected by maturational variables. These results are consistent with previous work demonstrating similar effects with questionnaire data (Baranek et al., 2006), but extend the findings specifically across three sensory modalities and two contexts (social and nonsocial) using an observational lab measure, the Sensory Processing Assessment (SPA). Mental age accounted for a significantly greater proportion of the variance than chronological age in explaining decreasing hyporesponsiveness as a function of maturation across all three groups of children. Thus, as mental abilities increased, children in all three groups became more responsive to sensory stimuli across social and nonsocial contexts. This may indicate maturation in neural mechanisms underlying general sensory processing and attention abilities, improvements in general learning, and/or development of compensatory strategies. However, our findings further demonstrated a novel interaction between group and slope (i.e., developmentally-related decrease in hyporesponsiveness) that more fully explicated the nature of these behaviors. At the youngest mental ages (6 months), group differences were significant and large, but by 60 months, these differences were no longer 
statistically significant. Thus, indicators of sensory hyporesponsiveness were most sensitive to group differences at the lowest mental ages, with the autism group faring the worst.

The methodology used in this study has advantages over previous studies in this area and helps to shed light on why discrepancies exist among findings in previous studies. First, the majority of studies in this area have utilized between-group designs taking a narrower crosssection of chronological age and matching groups on one or more key variables (e.g., mental age). Although several studies investigated the differential contextual effects (social versus nonsocial) of hyporesponsiveness in autism (e.g., Dawson et al., 1998; Dawson et al., 2004), most have not considered possible interactions between generalized hyporesponsiveness and developmental level, or the association of generalized hyporesponsiveness to broader outcomes.

Our study demonstrates a more complex picture of the developmental psychopathology of sensory hyporesponsiveness. The maturational level at which behaviors are sampled impacts directly upon the degree to which these deficits are apparent in children with autism. Furthermore, the developmental mechanisms underlying changes in behavioral responsiveness appear more critical than stimulus context (i.e., social or nonsocial) in detecting group differences as well as predicting to broader social-communication outcomes. The implications of this work may be relevant for identifying early risk factors - that is, at lower maturational levels, items tapping generalized hyporesponsiveness (i.e., orienting to novel social and nonsocial sensory stimuli) may be useful to identify children at risk for autism as well as those with other developmental delays, but the sensitivity and utility of such items potentially decreases as children's cognitive capacities mature. Although the literature is mixed with respect to the presence of early sensory symptoms in autism, few studies included sensory measures and/or relied heavily on retrospective parent-reports that may be less sensitive to these features in infancy. Several studies have reported early manifestations of sensory features either preceding or occurring simultaneously with other symptoms of autism by 12 months of age (Baranek, 1999; Dalhgren \& Gillberg, 1989; Zwaigenbaum et al., 2005).

Our findings also have implications for understanding the development of generalized sensory orienting processes in early childhood and the association of deficits in orienting to broader social-communicative outcomes. Previous research in autism indicated that social orienting was correlated with joint attention (Dawson et al., 2004), but effects for nonsocial orienting were not equitably examined in relation to joint attention and language variables. Our findings further clarify the nature of these associations, indicating that lack of orienting to both social and nonsocial sensory stimuli is associated with lower joint attention in children with autism, as well as those with DD or typical development, and this association is strongest at lower mental ages. Thus, we theorize that orienting to sensory stimuli is a domain-general process (occurring in both social and nonsocial contexts) that is foundational to the development of joint attention, for all groups of children. Although different neurological mechanisms may subserve initiation of joint attention (anterior attentional system) versus response to joint attention (posterior attentional system) (Mundy \& Newell, 2007; Mundy \& Jarrold, 2010), both processes appear associated with earlydeveloping skills in orienting to sensory stimuli based on our findings. Hyporesponsiveness to sensory stimuli during early critical periods for infants at-risk for autism would likely interact with other core deficits of autism, and thus, hypothetically may produce cascading effects on more complex developmental skills, particularly in the social-communication domain. As Mundy and Jarrold (2010) stated, the efficiency of social learning and social cognition results from the basic processes of the integration of self-initiated visual attention as well as the ability to process and follow the visual attention of others. With practice and experience, these co-active systems allow the infant to attend to and learn from multiple 
sources of social information and receive socially-contingent responses from other people. Bjorne, Johansson and Balkenius (2006) discuss the possible implications of prolonged difficulties in attention disengagement (that are one potential explanation of orienting difficulties) among children with autism for complex contextual learning. They posit that this would be especially problematic for social learning. Although our data suggest that children with autism demonstrate individual differences in the rate of acquisition of sensory orienting skills (i.e., normalize responses through maturation, experience, and/or intervention at different ages), the lost opportunities for learning during early developmental periods where sensory orienting is most critical may detrimentally impact the acquisition and/or quality of later-developing joint attention skills that are dependent on the interaction of both anterior and posterior neural mechanisms.

Our data on the associations between orienting to sensory stimuli and joint attention and language, even though cross-sectional, suggest a developmental model. For all groups, sensory hyporesponsiveness had a significant negative relation to joint attention at low mental ages, but by 60 months, the relation was no longer significant. Thus, by the maturational point at which the group differences in hyporesponsiveness have dissipated, individual variability in joint attention skills no longer is explained by ability to orient to sensory stimuli. As children mature and improve in their generalized orienting abilities, they may reach a threshold level such that responsiveness to sensory stimuli per se no longer imposes a constraint on their ability to engage in joint attention. From other research, however, we know that children with autism continue to experience problems, particularly in initiating joint attention, at older mental ages than children with other DD or typical development (Sigman \& Ruskin, 1999), suggesting other factors (e.g., motivation/social reward, effortful control, executive functions, etc.) may also constrain their development of joint attention skills (Mundy, 2011). Future studies need to use longitudinal methods, including an evaluation of non-linear trajectories and mediating variables, to unravel the complex interactions between early- and later-developing symptoms across different developmental domains.

In partial contrast to the lack of group differences in the analyses involving the correlation of sensory responsiveness and joint attention, the language skills of children with autism showed a statistically significant association with sensory responsiveness that did not reach significance in the other two groups. The association we found between sensory hyporesponsiveness on a laboratory task, and lower communication is consistent with at least one other study that used a parent report measure with children with autism (Liss et al., 2006).

One striking finding was that $100 \%$ of TD children and more than $90 \%$ of children with DD oriented to auditory stimuli within three trials. Thus, in this very important modality for language learning, children without autism are orienting quite well to auditory stimuli even at very young mental ages. In contrast, children with autism were slower to orient to both nonsocial and social auditory stimuli, and less than half of the group oriented to name call within three trials. Research using physiological methods has similarly demonstrated latencies in auditory processing and hypothesized a relation to cortical maturation deficits in autism (Gage, Siegel, \& Roberts, 2003). The inverse relation between hyporesponsiveness and language development in the autism group in our study hypothetically may reflect the aforementioned cascading impact of the orienting difficulties among children with autism.

These findings raise some complex questions regarding group differences in pathways subserving language learning and potential mediators of language outcomes. Future longitudinal studies with larger samples and multi-modal measures are needed to test 
developmental transactions among sensory hyporesponsiveness, joint attention, and language development across diagnostic groups.

\section{Specificity of Hyporesponsiveness to Autism: Effects of Context}

Specificity of deficits in autism may be best understood in a developmental context. Orienting skills are a key to early social engagement, environmental exploration and learning. As mentioned above, the autism group oriented less to all sensory stimuli compared with controls and this was particularly evident at younger mental ages. These findings provide support for theories of generalized deficits in sensory processing and/or attention, rather than solely a social cognitive deficit, that may underlie hyporesponsiveness to both social and nonsocial sensory stimuli in young children with autism (e.g., Harris et al., 1999; Townsend et al., 1999; Zwaigenbaum et al., 2005).

Adding to the findings of Dawson et al. $(1998 ; 2004)$ who concluded that social orienting was specifically associated with joint attention, the present study demonstrates that nonsocial sensory orienting is also associated with joint attention, and this finding is evident across all three groups of children. Our study further clarifies these associations, indicating that maturational variables may account for some of the individual differences. Specifically, the associations between sensory responsiveness and joint attention are greatest at very young mental ages when perhaps learning opportunities are more dependent upon the integrity of reflexive attentional processes, but decline in importance at higher mental ages as volitional mechanisms play a larger role in social learning. However, given that children with autism showed larger impairments in responsiveness to social than nonsocial stimuli, there may be an interaction of two mechanisms underlying this profile. Our findings are consistent with theories purported by Mundy and colleagues $(2007 ; 2010 ; 2011)$ that deficits in autism may result from difficulties in the integration of two attentional neural networks, a posterior system supporting early-developing and more reflexive aspects of generalized sensory orienting and response to joint attention, and an anterior system supporting laterdeveloping and more volitional social-cognitive behaviors including initiation of joint attention. Deficits in the later-developing anterior system may be linked to difficulty processing social rewards in autism and further explain why social orienting behaviors are often reported to be more problematic than nonsocial orienting behaviors at later developmental stages.

Interestingly, neurobiological and neurophysiological findings in autism have implicated aberrant functional connectivity (e.g., Belmonte et al., 2004; Minshew \& Hobson, 2008; Uhlhaas \& Singer, 2006) that may arise early in development and involve a variety of networks and structures (e.g., amygdala, dorsolateral prefrontal cortex, parietal lobe, cerebellum and superior temporal sulcus) associated with orienting to novelty, multisensory integration and/or disengagement of visual attention (Dawson et al., 1998; Macaluso, Frith, \& Driver, 2001; Tommerdahl, Tannan, Holden, \& Baranek, 2008; Townsend et al., 1999). Further research using cutting edge technologies is needed to unravel the developmental neurobiology underlying sensory hyporesponsiveness in autism.

\section{Methodological Considerations}

This study has several methodological advantages over previous work. Past studies on the sensory response patterns of children with autism relied heavily on caregiver report instruments (Baranek et al., 2006; Kientz \& Dunn, 1997; Lane et al., 2010; Talay-Ongan \& Wood, 2000; Watling, Deitz, \& White, 2001) that are prone to recall biases, situational differences, and developmental expectations affecting perceptions of behavior. We utilized a laboratory task to measure observed levels of sensory hyporesponsiveness. Direct observation-based sensory assessments may provide a more controlled and sensitive 
measure of hyporesponsiveness than parent report measures in early development (Baranek et al., 2008).

Although previous studies have provided preliminary evidence to address the question of context (Dawson et al., 1998; Swettenham et al., 1998), the present study extends the literature by examining sensory patterns across three modalities (tactile, auditory and visual) as well as two contexts (social and nonsocial) with a sample of young children with autism and matched controls. The use of a mixed model regression analysis with a large sample and broader age range allowed a more direct test for group differences while accounting for developmentally-related changes not previously studied systematically. Furthermore, this study confirms an association of sensory orienting to broader developmental outcomes in joint attention and language development in children with autism.

Limitations include the small number of stimuli in each condition that precluded directly analyzing group differences by modality, and also, floor effects of the SPA (i.e., many children receiving zero scores) at the highest developmental ages. Comparisons across modalities were not made since the physical properties of stimuli are difficult to equate across sensory modalities. Although the naturalistic paradigm provided ecological validity, future studies may wish to implement computerized tasks to experimentally equate the psychophysical properties of stimuli across modalities in social and nonsocial contexts, present greater numbers of trials for each stimulus, as well as control for possible confounding effects of live "social" administration for both social and nonsocial items.

Cross-sectional designs controlling for maturational variables allow invaluable inferences about developmental mechanisms underlying psychopathology, however, longitudinal studies are needed to more definitively answer questions regarding developmental change and long-range prediction to broader outcomes. Future studies may also wish to further differentiate high level from low level JA behaviors with more detailed coding procedures to determine to what extent these vary as a function of maturational variables and diagnostic group. Although the use of a mixed DD group allows for some generalization, future studies could investigate differential associations/disassociations that potentially exist across homogeneous subsamples of children with various types of DD to further our understanding of the developmental psychopathology and specificity of these phenomena.

\section{Acknowledgments}

This research was supported in part by a grant from the National Institute for Child Health and Human Development (R01-HD42168). We thank the families whose participation made this study possible, and the staff who collected and processed data for this project.

\section{REFERENCES}

Baranek, GT. Sensory Experiences Questionnaire (SEQ). University of North Carolina at Chapel Hill; 1999a. Unpublished manuscript

Baranek, GT. Sensory Processing Assessment for Young Children (SPA). University of North Carolina at Chapel Hill; 1999b. Unpublished manuscript

Baranek GT. Autism during infancy: A retrospective video analysis of sensory-motor and social behaviors at 9-12 months of age. Journal of Autism and Developmental Disorders. 1999; 29(3): 213-224. [PubMed: 10425584]

Baranek GT, David FJ, Poe MD, Stone WL, Watson LR. Sensory Experiences Questionnaire: Discriminating sensory features in young children with autism, developmental delays, and typical development. Journal of Child Psychology and Psychiatry. 2006; 47(6):591-601. [PubMed: 16712636] 
Baranek GT, Roberts JE, David FJ, Sideris J, Mirrett PL, Hatton DD, et al. Developmental trajectories and correlates of sensory processing functions in young boys with fragile $\mathrm{X}$ syndrome. Physical and Occupational Therapy in Pediatrics. 2008; 28(1):79-98. [PubMed: 18399048]

Bayley, N. Bayley Scales of Infant Development-Second Edition (BSID-II). Psychological Corporation; San Antonio, TX: 1993.

Belmonte MK, Allen G, Beckel-Mitchener A, Boulanger LM, Carper RA, Webb SJ. Autism and abnormal development of brain connectivity. The Journal of Neuroscience. 2004; 24(42):92289231. [PubMed: 15496656]

Ben-Sasson A, Hen L, Fluss R, Cermak SA, Engel-Yeger B, Gal E. A meta-analysis of sensory modulation symptoms in individuals with autism spectrum disorders. Journal of Autism and Developmental Disorders. 2009; 39:1-11. [PubMed: 18512135]

Bjorne P, Johansson B, Balkenius C. Effects of early sensorimotor disorder on contextual learning in autism. Revue européenne de psychologie appliqué. 2006; 56:247-252.

Boyd BA, Baranek GT, Sideris J, Poe MD, Watson LR, Patten E, Miller H. Sensory features and repetitive behaviors in children with autism and developmental delays. Autism Research. 2010; 3(2):78-87. [PubMed: 20437603]

Brady NC, Steeples T, Fleming K. Effects of prelinguistic communication levels on initiation and repair of communication in children with disabilities. Journal of Speech, Language, and Hearing Research. 2005; 48(5):1098-1113.

Dahlgren SO, Gillberg C. Symptoms in the first two years of life: A preliminary population study of infantile autism. European Archives of Psychology and Neurological Sciences. 1989; 238(3):169174.

Dawson G, Meltzoff AN, Osterling J, Rinaldi J, Brown E. Children with autism fail to orient to naturally occurring social stimuli. Journal of Autism and Developmental Disorders. 1998; 28(6): 479-485. [PubMed: 9932234]

Dawson G, Toth K, Abbott R, Osterling J, Munson J, Estes A, Liaw J. Early social attention impairments in autism: Social orienting, joint attention, and attention to distress. Developmental Psychology. 2004; 40(2):271-283. [PubMed: 14979766]

Farroni T, Simion F, Umiltà C, Barba BD. The gap effect in newborns. Developmental Science. 1999; 2(2):174-186.

Gage N, Siegel B, Roberts T. Cortical auditory system maturational abnormalities in children with autism disorder: An MEG investigation. Developmental Brain Research. 2003; 144(2):201-210. [PubMed: 12935917]

Gotham K, Risi S, Pickles A, Lord C. The autism diagnostic observation schedule (ADOS): Revised algorithms for improved diagnostic validity. Journal of Autism and Developmental Disorders. 2007; 37(4):613-627. [PubMed: 17180459]

Grandin T. Emergence: Labeled autistic. New York: Warner Books. 1996

Greenspan S, Wieder S. Developmental patterns and outcomes in infants and children with disorders in relating and communicating: A chart review of 200 cases of children with autistic spectrum diagnoses. Journal of Developmental and Learning Disorders. 1997; 1(1):87-141.

Harris NS, Courchesne E, Townsend J, Carper RA, Lord C. Neuroanatomic contributions to slowed orienting of attention in children with autism. Cognitive Brain Research. 1999; 8:61-71. [PubMed: 10216274]

Hart, C. Without reason: A family copes with two generations of autism. NAL; New York: 1991.

Hirstein W, Iversen P, Ramachandran VS. Autonomic responses of autistic children to people and objects. Proceedings of the Royal Society of London. Biological Sciences. 2001; 268(1479):18831888.

Hunnius S, Geuze RH. Gaze shifting in infancy: A longitudinal study using dynamic faces and abstract stimuli. Infant Behavior and Development. 2004; 27(3):397-416.

Hurwitz S. Joint attention revisited: Examining heterogeneity among children with autism. Dissertation Abstracts International. 2010; 71(08) from ProQuest Digital Dissertations database. (Publication No. AAT 3409920).

Johnson MH. Cortical maturation and the development of visual attention in early infancy. Journal of Cognitive Neuroscience. 1990; 2:81-95. 
Jones RSP, Quigney C, Huws JC. First hand accounts of sensory perceptual experiences in autism: A qualitative analysis. Journal of Intellectual and Developmental Disability. 2003; 28:112-121.

Kientz MA, Dunn W. A comparison of the performance of children with and without autism on the Sensory Profile. American Journal of Occupational Therapy. 1997; 51(7):530-537. [PubMed: 9242859]

Lane AE, Young RL, Baker AEZ, Angley MT. Sensory processing subtypes in autism: Association with adaptive behavior. Journal of Autism and Developmental Disorders. 2010; 40:112-122. [PubMed: 19644746]

Landa RJ, Holman KC, Garrett-Mayer E. Social and communication development in toddlers with early and later diagnosis of autism spectrum disorders. Archives of General Psychiatry. 2007; 64(7):853-864. [PubMed: 17606819]

Leekam SR, Hunnisett E, Moore C. Targets and cues: Gaze-following in children with autism. Journal of Child Psychology and Psychiatry. 1998; 39(7):951-962. [PubMed: 9804028]

Leekam SR, Nieto C, Libby SJ, Wing L, Gould J. Describing the sensory abnormalities of children and adults with autism. Journal of Autism and Developmental Disorders. 2007; 37(5):894-910. [PubMed: 17016677]

Leekam SR, Ramsden CA. Dyadic orienting and joint attention in preschool children with autism. Journal of Autism and Developmental Disorders. 2006; 36(2):185-197. [PubMed: 16502142]

Little L, Freuler A, Houser MB, Guckian L, Carbine K, David FJ, et al. Brief Report. Psychometric Validation of the Sensory Experiences Questionnaire. American Journal of Occupational Therapy. 2011; 65(2):207-210. [PubMed: 21476368]

Liss M, Saulnier C, Fein D, Kinsbourne M. Sensory and attention abnormalities in autistic spectrum disorders. Autism. 2006; 10(2):155-172. [PubMed: 16613865]

Lord, C.; Rutter, M.; DiLavore, P.; Risi, S. The Autism Diagnostic Observation Schedule (ADOS). Western Psychological Services; Los Angeles: 1999.

Lord C, Rutter M, Le Couteur A. Autism Diagnostic Interview-Revised: A revised version of a diagnostic interview for caregivers of individuals with possible pervasive developmental disorders. Journal of Autism and Developmental Disorders. 1994; 24(5):659-685. [PubMed: 7814313]

Macaluso E, Frith CD, Driver J. Multimodal mechanisms of attention related to rates of spatial shifting in vision and touch. Experimental Brain Research. 2001; 137:445-454.

Miller LJ, Anzalone ME, Lane SJ, Cermak SA, Osten ET. Concept evolution in sensory integration: A proposed nosology for diagnosis. American Journal of Occupational Therapy. 2007; 61(2):135140. [PubMed: 17436834]

Miller, LJ.; Reisman, JE.; McIntosh, DN.; Simon, J. An ecological model of sensory modulation: Performance of children with fragile $\mathrm{X}$ syndrome, autistic disorder, attention-deficit/hyperactivity disorder, and sensory modulation dysfunction.. In: Smith-Roley, S.; Blanche, EI.; Schaaf, RC., editors. Understanding the nature of sensory integration with diverse populations. Therapy Skill Builders; San Antonio, TX: 2001. p. 57-88.

Minshew NJ, Hobson JA. Sensory sensitivities and performance on sensory perceptual tasks in highfunctioning individuals with autism. Journal of Autism and Developmental Disorders. 2008; 38(8): 1485-1498. [PubMed: 18302014]

Mullen, EM. Mullen Scales of Early Learning (AGS Edition). Western Psychological Services; Los Angeles: 1995.

Mundy, P.; Delgado, C.; Block, J.; Venezia, M.; Hogan, A.; Seibert, J. A manual for the abridged Early Social Communication Scales (ESCS). University of Miami, Department of Psychology; Coral Gables, FL: 2003.

Mundy, P.; Neal, R. Neural plasticity, joint attention, and a transactional social-orienting model of autism.. In: Glidden, LM., editor. International review of research in mental retardation: Vol. 23. Autism. Academic Press; San Diego, CA: 2001. p. 139-168.

Mundy P, Newell L. Attention, joint attention and social cognition. Current Directions in Psychological Science. 2007; 16(5):269-274. [PubMed: 19343102]

Mundy P, Jarrold W. Infant joint attention, neural networks and social cognition. Neural Networks. 2010; 23(8-9):985-997. [PubMed: 20884172] 
Mundy, P. The social behavior of autism: A parallel and distributed information processing perspective.. In: Amaral, DG.; Dawson, G.; Geschwind, DH., editors. Autism Spectrum Disorders. Oxford University Press; NY: 2011. p. 149-171.

Nadig AS, Ozonoff S, Young GS, Rozga A, Sigman M, Rogers SJ. A prospective study of response to name in infants at risk for autism. The Journal of Pediatrics. 2007; 161(4):378-383.

O'Neill M, Jones RS. Sensory-perceptual abnormalities in autism: A case for more research? Journal of Autism and Developmental Disorders. 1997; 27(3):283-293. [PubMed: 9229259]

Posner MI, Rothbart MK. Research on attention networks as a model for the integration of psychological science. Annual Review of Psychology. 2007; 58:1-23.

Rogers SJ, Ozonoff S. Annotation: What do we know about sensory dysfunction in autism? A critical review of the empirical evidence. Journal of Child Psychology and Psychiatry. 2005; 46(12):12551268. [PubMed: 16313426]

Roid, GH.; Miller, LJ. Leiter International Performance Scale Revised. Stoelting Co.; Wood Dale, IL: 1997.

Rothbart MK, Posner MI, Rosicky J. Orienting in normal and pathological development. Development and Psychopathology. 1994; 6(4):635-652.

Schneider ML, Moore CF, Gajewski LL, Larson JA, Roberts AD, Converse AK. Sensory processing disorder in a primate model: Evidence from a longitudinal study of prenatal alcohol and prenatal stress effects. Child Development. 2008; 79(1):100-113. [PubMed: 18269511]

Schopler, E.; Reichler, RJ.; Renner, BR. The Childhood Autism Rating Scale. Western Psychological Services; Los Angeles: 1986.

Sigman M, Ruskin E. Continuity and change in the social competence of children with autism, Down syndrome, and developmental delays. Monographs of the Society for Research in Child Development. 1999; 64(1):1-114. [PubMed: 10412222]

Siller M, Sigman M. Modeling Longitudinal Change in the Language Abilities of Children With Autism: Parent Behaviors and Child Characteristics as Predictors of Change. Developmental Psychology. 2008; 44(6):1691-1704. [PubMed: 18999331]

Sparrow, S.; Balla, D.; Cicchetti, D. Vineland Adaptive Behavior Scales. American Guidance Service; Circle Pines, MN: 1984.

Stata Press. Longitudinal/Panel-Data Reference Manual: Release 10. Author; College Station: 2007.

Stone WL, Ousley OY, Yoder PJ, Hogan KL, Hepburn SL. Nonverbal communication in two- and three-year-old children with autism. Journal of Autism and Developmental Disorders. 1997; 27(6): 677-696. [PubMed: 9455728]

Swettenham J, Baron-Cohen S, Charman T, Cox A, Baird G, Drew A, et al. The frequency and distribution of spontaneous attention shifts between social and nonsocial stimuli in autistic, typically developing, and nonautistic developmentally delayed infants. Journal of Child Psychology and Psychiatry. 1998; 39(5):747-753. [PubMed: 9690937]

Talay-Ongan A, Wood K. Unusual sensory sensitivities in autism: A possible crossroads. International Journal of Disability, Development and Education. 2000; 47(2):201-212.

Tommerdahl M, Tannan V, Holden JK, Baranek GT. Absence of stimulus-driven synchronization effects on sensory perception in autism: Evidence for local underconnectivity? Behavioral and Brain Functions. 2008; 4:19. [PubMed: 18435849]

Townsend J, Courchesne E, Covington J, Westerfield M, Harris NS, Lyden P, et al. Spatial attention deficits in patients with acquired or developmental cerebellar abnormality. Journal of Neuroscience. 1999; 19(13):5632-5643. [PubMed: 10377369]

Uhlhaas PJ, Singer W. Neural synchrony in brain disorders: Relevance for cognitive dysfunctions and pathophysiology. Neuron. 2006; 52(1):155-168. [PubMed: 17015233]

Watling RL, Deitz J, White O. Comparison of Sensory Profile scores of young children with and without autism spectrum disorders. American Journal of Occupational Therapy. 2001; 55(4):416423. [PubMed: 11723986]

Wetherby AM, Watt N, Morgan L, Shumway S. Social communication profiles of children with autism spectrum disorders late in the second year of life. Journal of Autism and Developmental Disorders. 2007; 37(5):960-975. [PubMed: 17066310] 
Zimmerman, IL.; Steiner, VG.; Pond, RE. Preschool Language Scale, Fourth Edition (PLS-4). The Psychological Corporation; 2002.

Zwaigenbaum L, Bryson S, Rogers T, Roberts W, Brian J, Szatmari P. Behavioral manifestations of autism in the first year of life. International Journal of Developmental Neuroscience. 2005;

23(2-3):143-152. [PubMed: 15749241] 


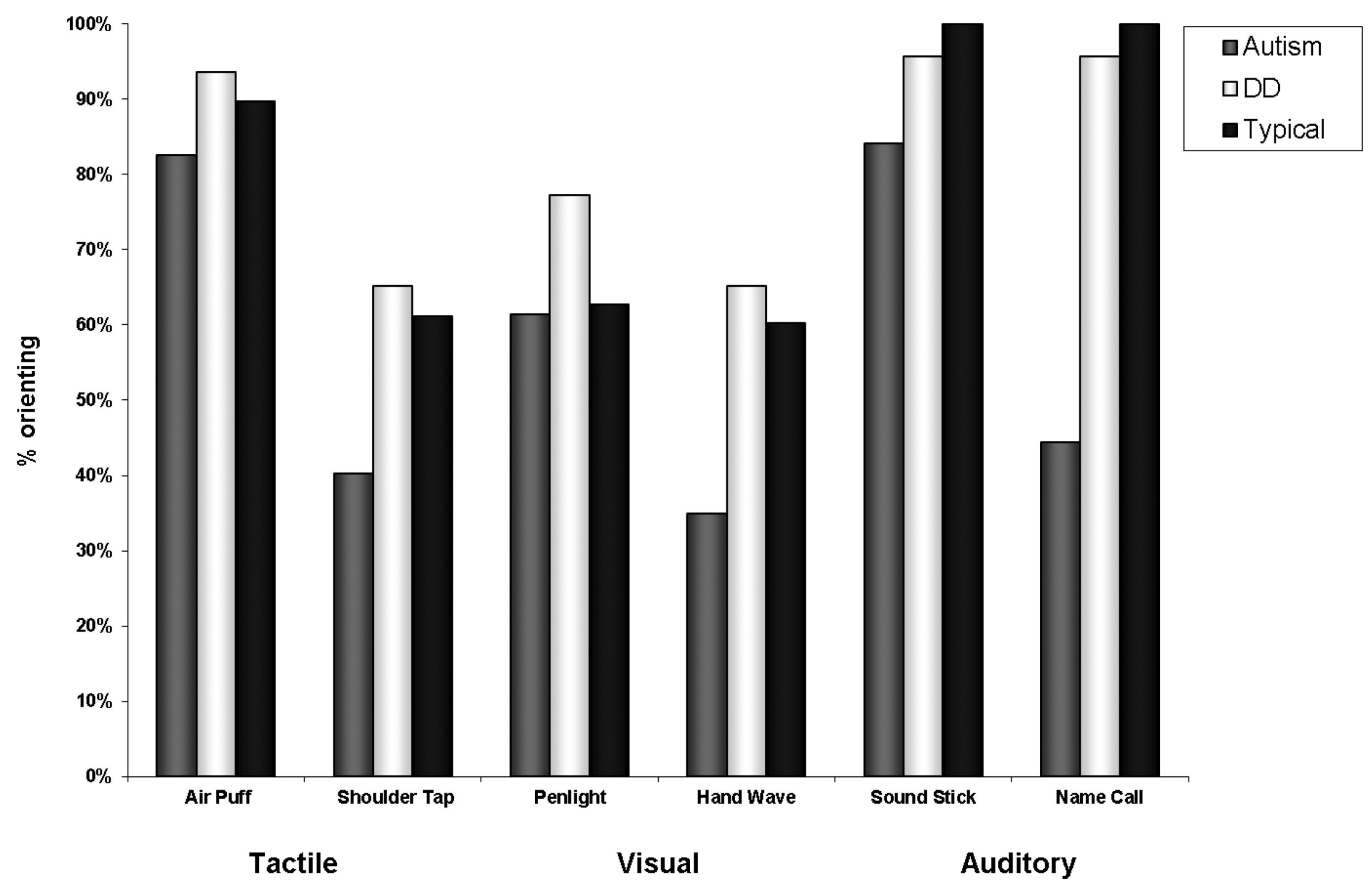

Figure 1.

Frequencies of subjects who oriented within three trials across the six stimuli. 


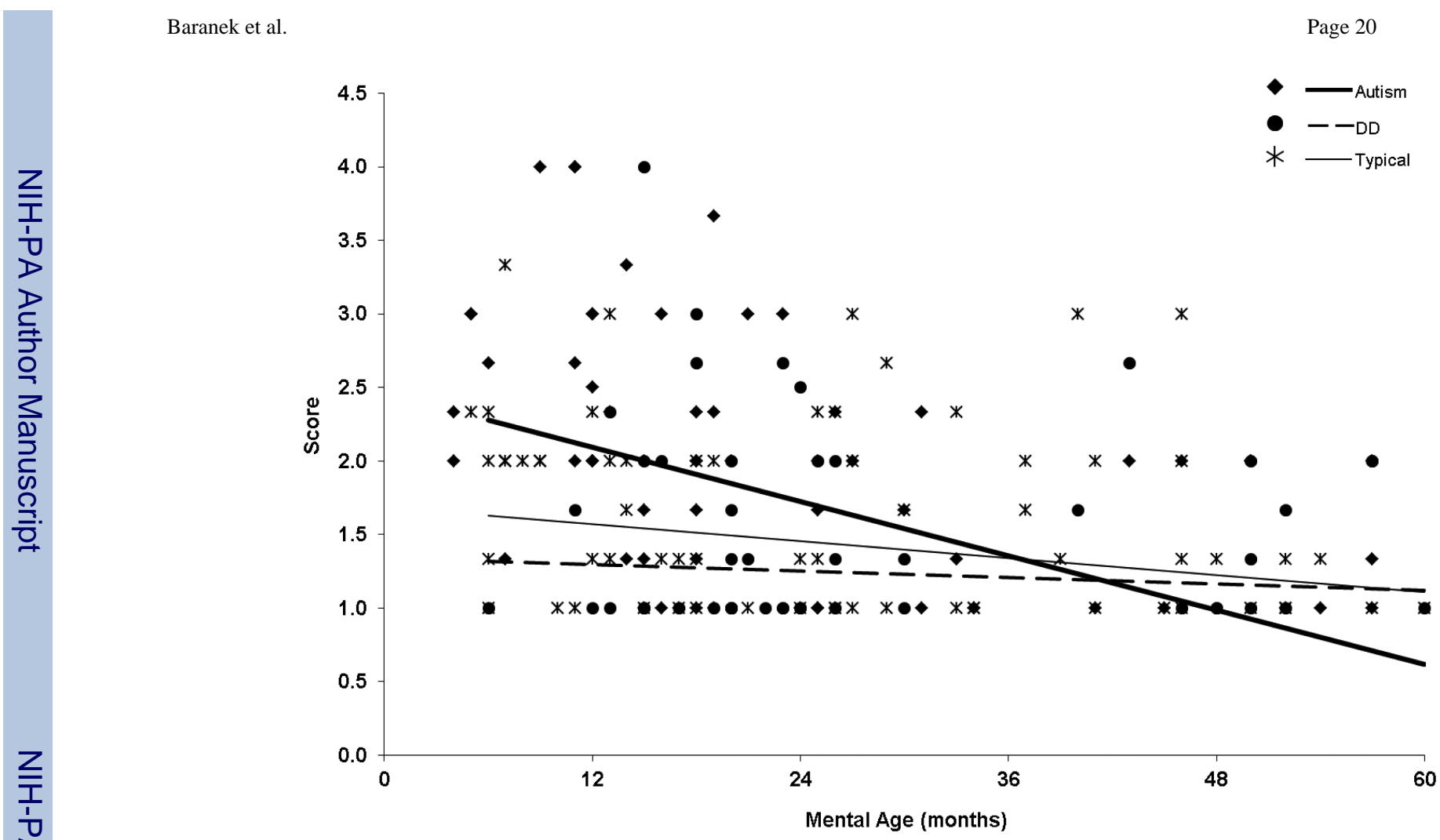

Figure 2.

Hyporesponsiveness to nonsocial sensory stimuli as a function of MA controlling for CA. 


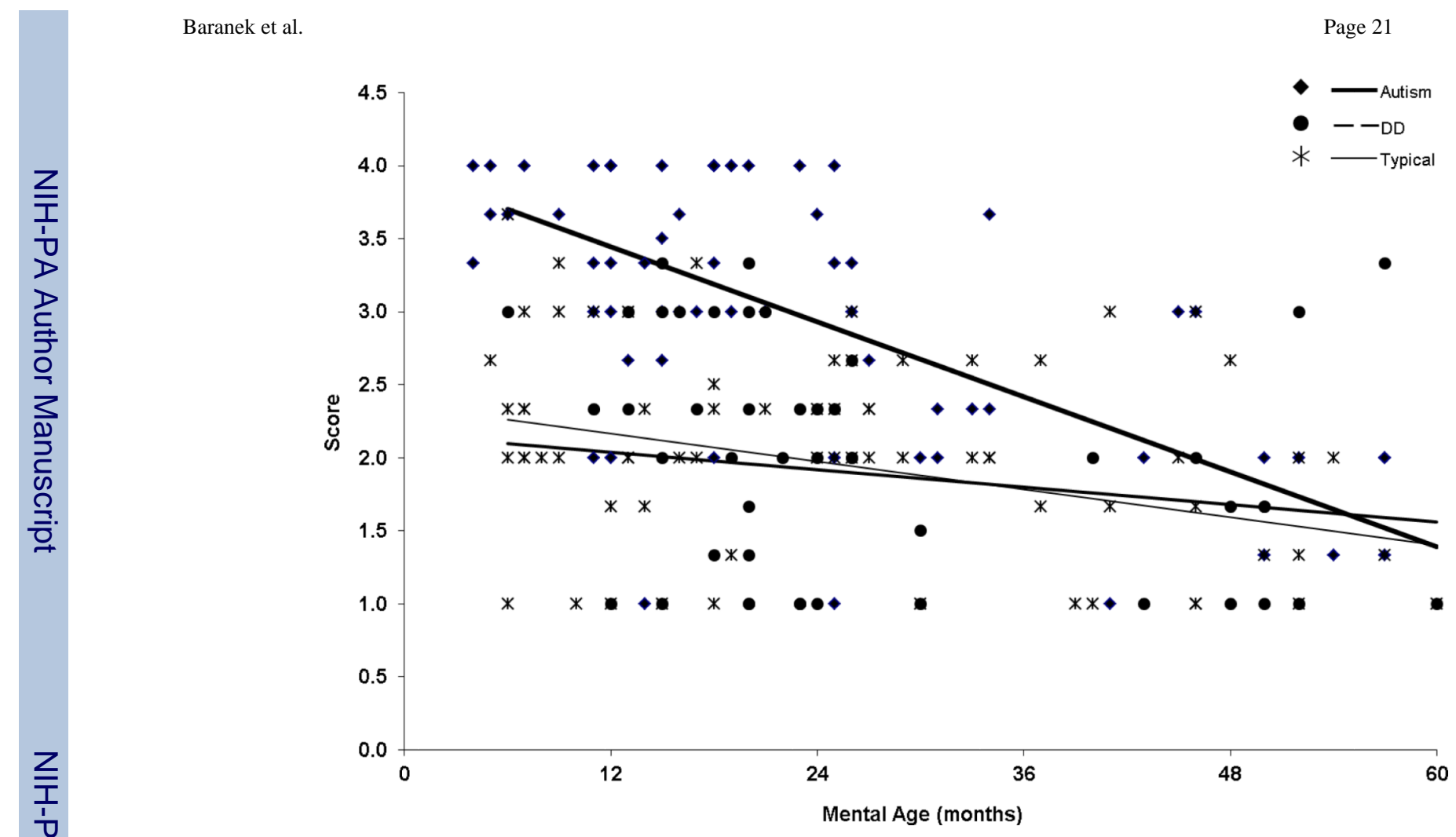

Figure 3.

Hyporesponsiveness to social sensory stimuli as a function of MA controlling for CA. 


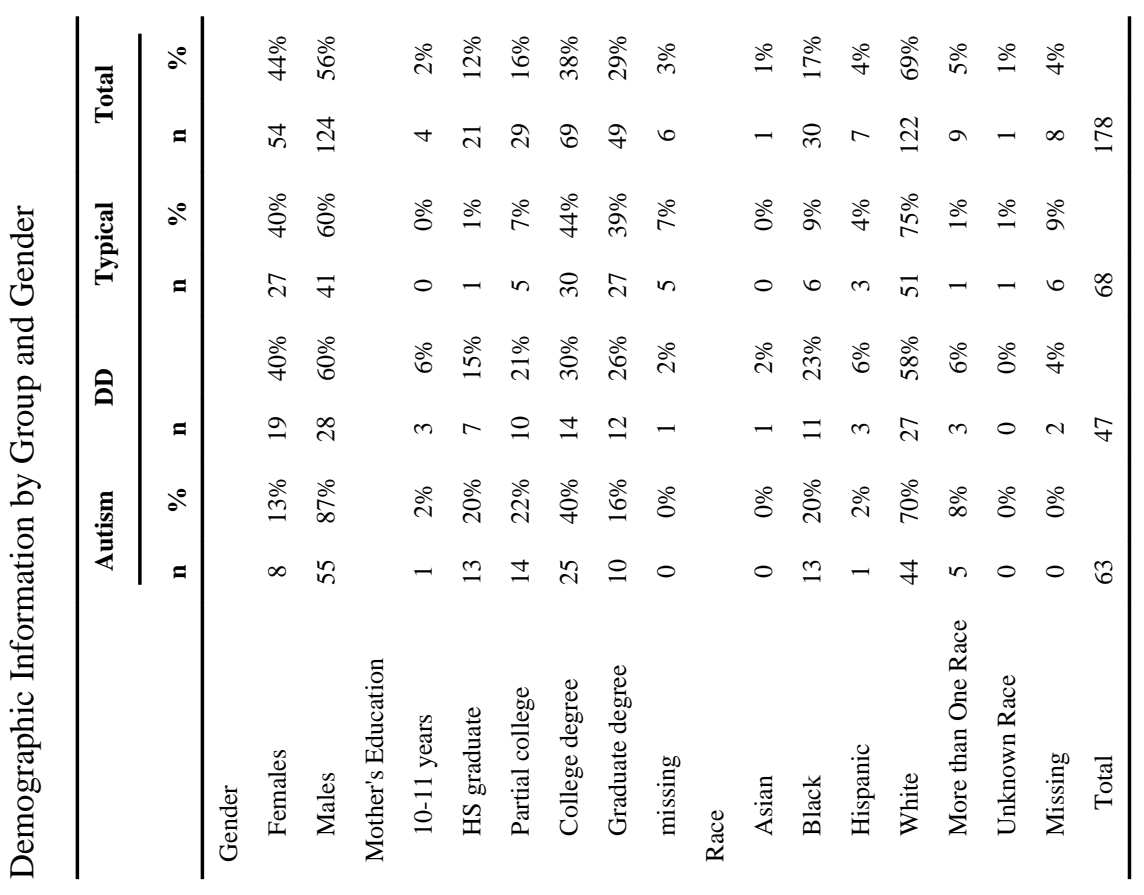




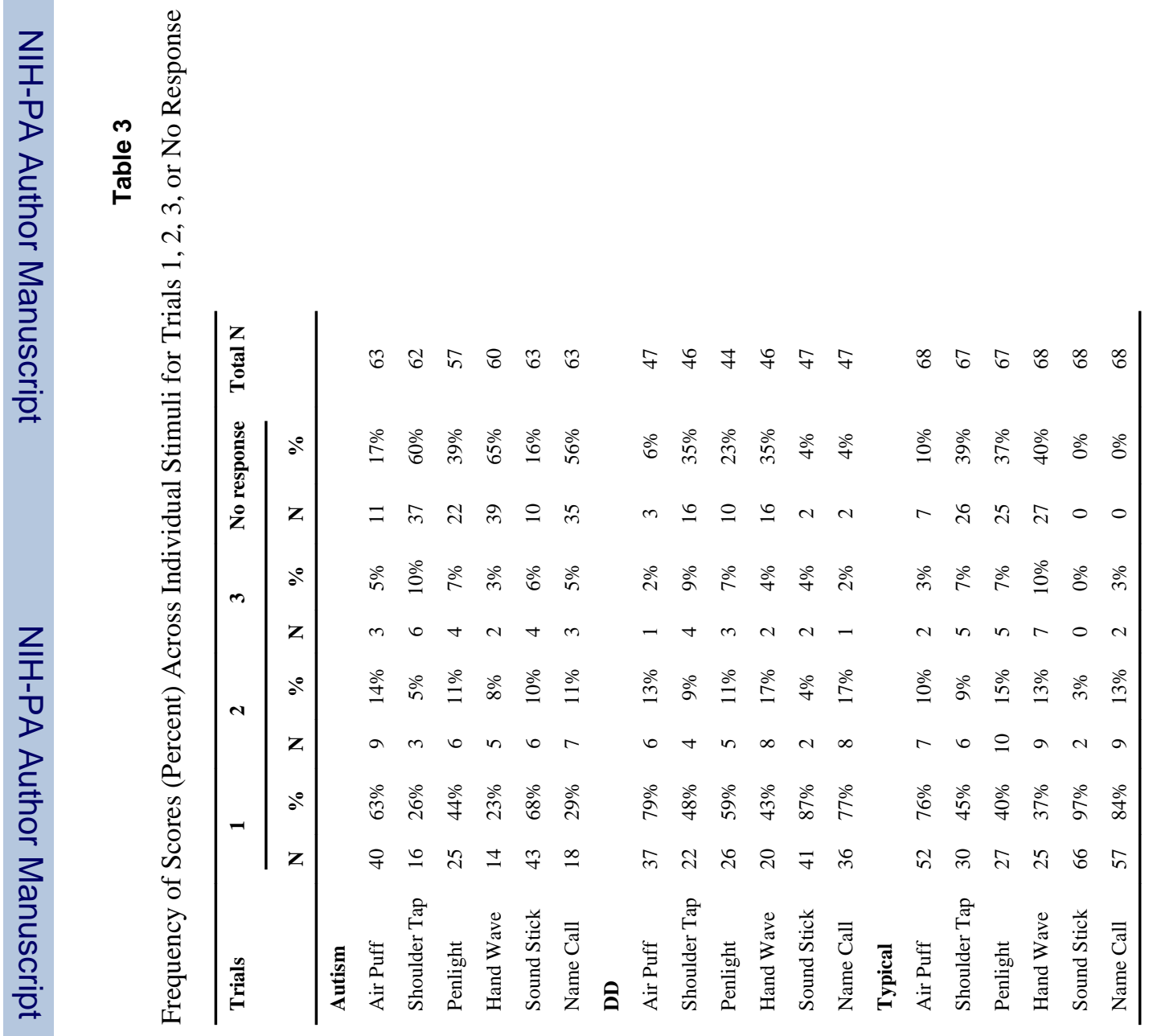




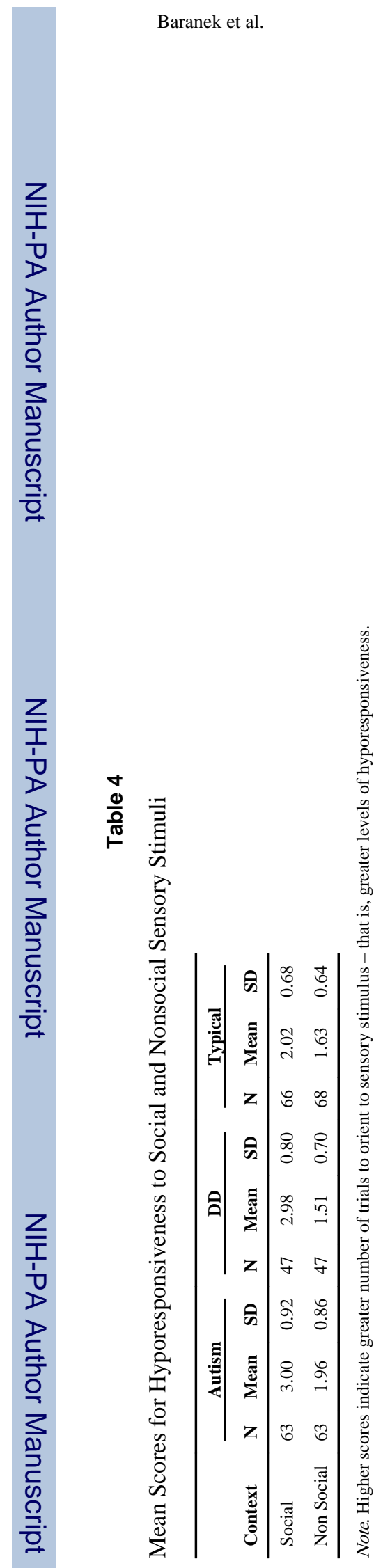

Page 25

Dev Psychopathol. Author manuscript; available in PMC 2014 May 01. 
Table 5

Censored Regression Analysis of Hyporesponsiveness (Controlling for CA)

\begin{tabular}{lcccc}
\hline & \multicolumn{1}{c}{ Chi } & $\boldsymbol{p}$ & & \\
\cline { 2 - 4 } Group & 4.50 & .106 & & \\
Group $\times$ MA & 7.76 & .021 & & \\
Group $\times$ Context & 13.83 & .001 & & \\
& & & & \\
\cline { 3 - 5 } & & $\boldsymbol{\beta}$ & $\mathbf{S E}$ & $\boldsymbol{p}$ \\
\cline { 3 - 5 } Non-social Average slope & -0.015 & 0.007 & .041 \\
Social Average slope & -0.021 & 0.007 & .003 \\
\hline
\end{tabular}




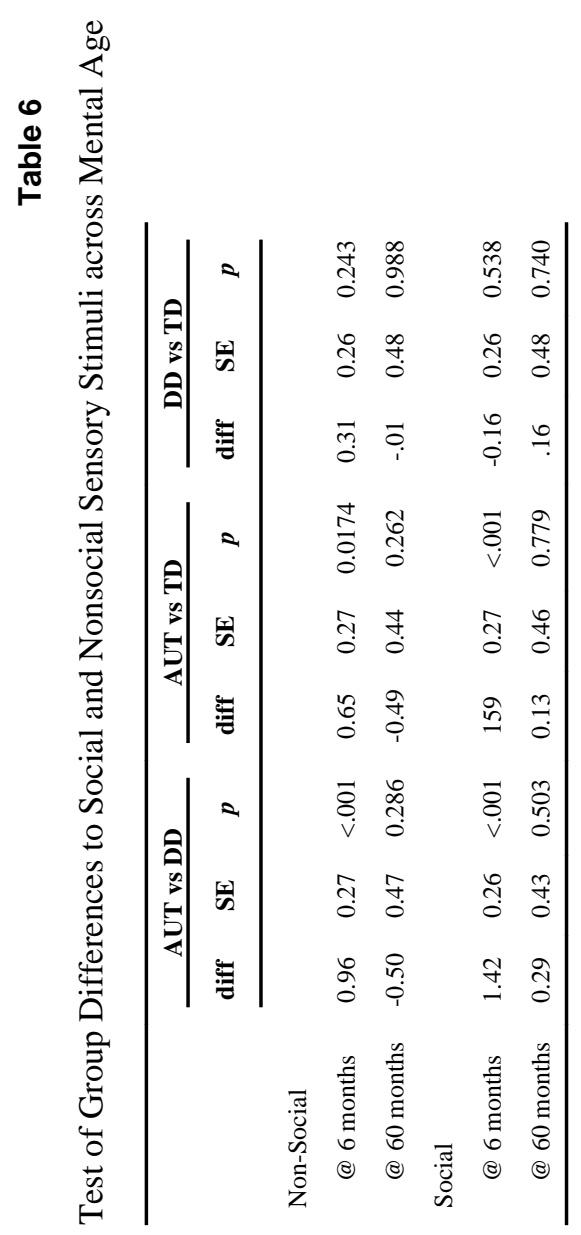

Dev Psychopathol. Author manuscript; available in PMC 2014 May 01. 